\title{
The study of Physics History Teaching in High School Physics
}

$$
\text { GAO Feng }{ }^{1, a} \text {, QU Qingling }{ }^{2, b}
$$
${ }^{1}$ College of Physics and Electronic Information, Baicheng Normal University, Baicheng, 137000,
China

\author{
${ }^{2}$ College of Physical Education, Baicheng Normal University, Baicheng, 137000, China \\ agaof317@163.com, bquqinglingkuaile@126.com
}

\section{Keywords: Physics History, The Class, Teaching}

\begin{abstract}
The teaching of history of physics is a concept changing with the continuous development of the times. In the current new curriculum reform, the school has put forward new requirements for the teaching of physics history in physics. In many foreign countries, the history of physics has been used as a model of teaching, and there is a strict requirement for the physics teachers to master the history of physics. Although the teaching of physics history in China is relatively late, but now we have a relatively mature and characteristic teaching system of physics history. This paper analyzes the current situation of physics classroom in senior high school, and studies the teaching of physics history in high school classroom.
\end{abstract}

\section{Introduction}

Since the new century, there are more requirements for the teaching level of teachers and teachers to guide students to learn. In the new curriculum, to cultivate students' scientific quality has attracted more and more attention. In high school physics teaching in the history of physics is conducive to cultivating students' innovative spirit, and also can achieve the new curriculum reform the standard of teaching. Innovation is a necessary condition for the development of science, cultivating students' innovative spirit can penetrate history of physics teaching can be achieved. For high school students, learning and understanding of physics knowledge is difficult, in order to allow students to understand the knowledge of physics, physics history in the teaching of physics teaching to strengthen students physical knowledge, memory, but also help students to understand the physical knowledge, to achieve the requirements of the curriculum reform [1].

In the physics teaching in high school in conclusion is generally carried out under the ideal condition. Because of this ideal state beyond the students' thinking, so the students understand easily controlled by subjective ideas, this knowledge understanding not easily confused. The effective introduction of the history of physics the establishment process of backtracking physical conception, it can avoid this situation. Before the new curriculum teaching in the new curriculum or teaching, make students physics by telling the first stand to establish a kind of physical thinking in the physicist's point of view, after gradually in-depth analysis of the knowledge to the students, the teaching can induce step by step to effectively improve the teaching level, but also can help students establish the correct physical mode of thinking.

\section{The Present Situation of the Teaching of the History of Physics}

In the present high school physics teaching, there are many deficiencies in the teaching of physics history, which are reflected in the following aspects:

In the college entrance examination, the history of physics examination content rarely get people's attention. Even if there is only related topics, such as "Which scientists found through experiments of magnetic effect of current?" this kind of simple facts of pure memory, physical thought and deep level is not reflected, which resulted in a physics teacher ignore the history of physics teaching [2].

The physics teacher knows the history of physics is not comprehensive, the teaching process can simply introduce a point, or even directly neglect it, the course of study is not to dig further the 
story behind the implied philosophy and scientists. The spirit of innovation and personality charm of scientists that they have not been delivered a good show in front of the students.

The teacher taught the history of physics is to the teaching task, but straightforward to explain the history of science. For example, in summing up the movement of the heavenly bodies through this chapter, the teacher will mostly simple description of the history of science related: "in ancient Greece, the light is produced by human eyes; in seventeenth Century, some people say the light is the particle, some say it's wave; until nineteenth Century, the continuous development of science and technology, people's understanding of light is also improved, found light also exist in the electromagnetic wave mode." if the teacher is just such a simple description of the history of physics, this will only make the physical classroom become more boring, this can not let the students master class, play to their strengths, not to mention the students physical love this class.

\section{The Educational Potential of the History of Physics}

The Teaching of the History of Physics can Stimulate Students' interest in Physics. Someone said: "no matter what, love is also good teachers and helpful friends." Goethe said: "no interest has no memory. Therefore, the key is to do a thing is interested in learning is the same, only one thing is to further understand the desire to love learning instead, I feel that learning is a very annoying thing, but the learning process will feel very happy. As it is difficult to learn physics subjects, if the lack of interest in learning is very difficult. Teachers can use in explaining the physical knowledge in local infiltration about the history of physics to arouse students the physical curiosity, when students of physical curiosity, and then they will love physics, high school physics teaching should help students further understand the knowledge in and enhance students' curiosity and seek knowledge of Physics Desire [3].

The History of Physics Education can Cultivate Students' rigorous Scientific Attitude and a Solid Study Style. We want to give scientists the rigorous scientific attitude as the starting point of our study and reference, and the reference point of most of the performance in the spirit of pragmatic and realistic scientific attitude, the expressive forms of the spirit and attitude of most directly reflected in their usual research life. Therefore, we should be most in the all facts and summarize the spirit of place, and learn from, and share with you the experience and achievements. For example in the Ohm's law in this section, we found that the difficult course in ohm Ohm's law for facts, understand the background of Ohm's law of Ohm's law was put forward through. Many twists and turns, as found in the early stage, this theory is not subject to the approval of others, he had a lot of pressure. People did not pay attention to this found him in ohms. The economy is very difficult, which leads to the ohmic depression, but he still insists on his research, eventually making Ohm's law obtained the approval of the scientific community. Explain like this in the physics classroom into the history of physics, not only can learn the basic laws of physics, scientists can also learn to scientific effort, at the same time they also told the students should learn to persevere the scientific attitude [4].

The History of Physics Education can Help Students Correct Mistakes in the Process of Thinking. The teaching practice shows that the history of physics can help teachers in the teaching process of senior high school physics make students establish the correct way of thinking in physics. For example, Newton's first law of motion physics thought this law was originally Aristotle first put out, he thought force is the reason of maintaining objects movement. As we pushed by hand on the desk the textbook, the book moves, when the hand not to push the book, the book does not move, it is suggested that the object is only in force when the movement, if removed from the force, objects will be stopped immediately. Two thousand years later, Galileo observed such a situation in life, when we are playing football when the foot to the ball a force makes the ball, but the ball in the air or rolling on the grass and not force, and the ball is still in motion. This example is just related to the point does not match, it means that the View is wrong. So we can draw new conclusions: capable of moving body under the action of forces but when removed from the force, motion will not immediately stop, namely force change motion of objects. 
The Way to Permeate the History of Physics in the Physics Class. The status of the history of physics in Physics Teaching in senior high school is not only to improve the requirements of quality education, but also an important aspect of physics teaching should focus on the future development. In order to use the history of physics for senior high school physics teaching, then gives some ways of teaching history of physics:

Elicited the Subject of the Lecture. The theory and practice of teaching show that, in order to have a good classroom effect, students should have the desire to learn, so that students will learn independently. The classroom can proceed smoothly, the key lies in the introduction to new lessons. Teachers by using the history of physics in the form of new curriculum teaching can make classroom atmosphere more active. For example, the use of the apple that Newton puzzled, "how can it fall apple" story to introduce the law of gravity, this thing that can arouse students the knowledge of the interest [5].

The Process of Giving Prominence to Physical Knowledge and the Methods of Physics. If we want to make students understand the background of physical knowledge, then the role of Physics History Teaching in classroom is particularly prominent. To accomplish this task, we need to infiltrate the history of physics. Therefore, in physics teaching, thinking method is more worthy of our learning.

Newton said: "The natural philosophy aims to find out the structure and function of nature, and try to summarize them into some of the common law and general law by observation and experiment to establish these rules, reasons and results are derived. These things let us know through the history of physics will let students understand them how is the use of creative thinking and rigorous attitude, meticulous research derived from scientific theorem, the process for the formation of the teaching significance of students' creative thinking.

Display the Beauty of Physics. Education policy also requires the teacher to show the charm of physics to the students in the physics classroom of senior high school physics. To seek the logic and simple method to study the material. Want to find material movement to the complex material movement is simplified into idealized simple physical model, such as the ratio of particle, we studied the light point charge. Again, with the aid of mathematical formula, using the function relationship and mathematical graphs to describe the complex physical phenomena, which reflects the simple beauty of physics.

\section{The Role of the History of Physics in the Classroom}

In scientific research, Professor Qian San Qiang has said that the history of physics plays an important role and puts forward his own opinion on how to carry out physics teaching. Another study of physics history can help students develop innovative ability. When Einstein created the theory of relativity, he described relativity as a specific problem. The relativity principle and the theory of electrodynamics of Maxwell-Lorentz were contradictory. Einstein's theory of relativity can let us have a deeper understanding of science, he is considering the problem of thinking beyond the tradition. So the proposed process in relativity, scientists consider the problem of thinking mode is the focus of our study. The social sciences also just need this kind of innovative thinking, and have a deep feeling of this kind of thought will be realized through the history of physics [6].

In high school physics classroom, teachers use the history of permeating physics to teach, which can effectively improve the quality of teaching. Teachers infiltrate the history of physics before students learn physics knowledge, so that students can understand the establishment process of physical knowledge and enable students to grasp the connotation of physical knowledge correctly. For example, in free fall experiments, Galileo used two weight difference within the falling speed of object comparison experiments show that Aristotle's conclusion is wrong, and also continue to own experiment to improve, in the process of using a comprehensive method. In the electrostatic force and gravitation law also use the analogy methods. So, summarizes previous thoughts in physics history are shown. Not only can be used in a theory, in other theory can also be applied to the learning process, so repeated, repeated use is absorbed, so as to achieve the purpose of improving the teaching quality. 
The history of physics can help students to establish a scientific spirit. Now has been found and summed up some theorems and laws, we learn or understand easily, but we always ignore is now enjoying the convenience is in the numerous failures, countless thoughts and countless times to complete the establishment of the process to overthrow. Through the research and teaching of the history of physics, scientific spirit to enable students to persevere for scientists is a comprehensive and correct understanding. As we think that success is not easy to achieve, is experienced in reaching the basis of countless failures. Edison and Mrs Curie's success, just confirms the above the point of view.

\section{Conclusion}

The research of teaching physics history in senior high school is very helpful for the existing physics teaching theory and teaching practice. The most important thing is how to maximize the role of physics history so as to achieve the purpose of improving the quality of Physics Teaching in senior high school. We analyzed and summarized several methods and principles used in the article, so that students could understand physics better and faster with the help of teachers' knowledge about physics history explained in class. What is the explanation of the history of physics can not only help the teachers to active classroom atmosphere, arouse the enthusiasm of students, also can cultivate students' interest in learning physics, developing students' divergent thinking and to cultivate their independent thinking ability is also a great help, can provide a new way of finding and solving problems for students, with a certain reference value and significance of high school physics teaching mode in the past only pay attention to physics teaching and the theory of knowledge on the teaching practice of the whole process. From the point of view, the history of Physics Teaching in senior high school physics penetration will be some extent to the senior high school physics provides a new way of teaching, play a certain role in the cultivation of students' ability.

\section{References}

[1] LI Qingtao. The application of physical concepts and the history of physics in Physics Teaching [J]. China Education Innovation Herald,2013,(30):84-84.

[2] LIU Xingyun. Giving full play to the educational function of the history of physics in Physics Teaching in high school[J]. Journal of Xingyi Normal University for Nationalities, 2007, (2):78-81.

[3] QIAN Changyan. The way to infiltrate the education of history of physics in Physics Teaching [J]. Modern Physics,1998,(3):34-36.

[4] CHENG Minhai. The function and Reform of Physics History Teaching[J]. Modern Physics, 1997, (6):26-28.

[5] LU Liangrong. Understanding of the function of Science Education in Physics History[J]. Jiangsu Education Research,2012,(25):28-30.

[6] SHEN Xianjia. Applying the history of physics to innovation of Physics Education[J]. Journal of Capital Normal University (Natural Science Edition), 1989, (3):75. 